\title{
Antiemetic therapy for multiple-day chemotherapy and additional topics consisting of rescue antiemetics and high-dose chemotherapy with stem cell transplant: review and consensus statement
}

\author{
Lawrence H. Einhorn • Steven M. Grunberg • \\ Bernardo Rapoport • Cynthia Rittenberg • Petra Feyer
}

Received: 30 March 2010 /Accepted: 11 May 2010/Published online: 26 May 2010

(C) Springer-Verlag 2010

\begin{abstract}
This paper will evaluate various topics related to chemotherapy-induced nausea and vomiting. The results published reflect a consensus conference convened in Perugia, Italy. The topics discussed include antiemetic therapy of multiple-day chemotherapy, high-dose chemotherapy, and rescue antiemetics.
\end{abstract}

Keywords Antiemetics · Multiday chemotherapy · Rescue antiemetics

Lawrence H. Einhorn is a Lance Armstrong Foundation Distinguished Professor of Medicine.

L. H. Einhorn $(\bowtie)$

Division of Hematology-Oncology,

Mel and Bren Simon Cancer Center, Indiana University,

535 Barnhill Room 473,

Indianapolis, IN 46202-5289, USA

e-mail: leinhorn@iupui.edu

\section{S. M. Grunberg}

University of Vermont Medical Center,

Burlington, VT 05401-1473, USA

B. Rapoport

Medical Oncology Centre of Rosebank,

2193 Johannesburg, South Africa

C. Rittenberg

Rittenberg Oncology Consultants,

Metairie, LA 70005, USA

P. Feyer

Clinic of Radiotherapy, Viventes Clinics Beniu-Needcoellin,

Berlin, Germany

\section{Introduction}

In 2004, an expert international panel convened in Perugia, Italy to discuss various issues involving chemotherapyinduced nausea and vomiting (CINV) and develop consensus statements [1]. This paper briefly will describe those previous deliberations, as well as add pertinent new information since the 2005 publication. As with the previous studies, guidelines are possible with 5-day cisplatin combination chemotherapy in germ cell tumors based upon phase III studies. However, there are no sufficiently powered studies to generate similar statements for the other additional topics in this paper. Guideline updates that provide no new evidence, but no change to recommendations, do not require substantial textural change [2].

\section{Multiple-day chemotherapy}

In adult oncology, there are adequate data to provide guidelines for clinical utility in patients receiving 5-day cisplatin combination chemotherapy in testicular cancer [1]. There are other regimens utilizing multiple-day chemotherapy such as ifosfamide or actinomycin-D, especially in a pediatric setting. However, there is a paucity of even phase II data in this setting to make any therapeutic recommendation.

Prior to the introduction of ondansetron, the first 5HT3 receptor antagonist, the typical testicular patient would experience 10 emetic episodes on day 1, 5 on day 2 , and decreasing emesis on succeeding days [3]. This trend has now actually been reversed with increasing nausea and vomiting on days $3-5$, and few, if any, patients are being subjected to the very severe CINV of those earlier days. 
The first phase II study of single agent ondansetron in this setting studied 35 patients, of whom 24 were chemonaive [4]. Ten patients (29\%) had no emesis and 18 (51\%), two or few episodes during the duration of therapy, with highest rate of complete protection $(77 \%)$ seen on day 1 . Subsequent phase III studies documented the value of adding dexamethasone [5] and the superiority of ondansetron to metoclopramide [6].

Palonosetron is a second-generation 5-HT3 receptor antagonist with a prolonged half-life. A phase II study evaluated palonosetron $0.25 \mathrm{mg}$ intravenously on days 1,3 , and 5 combined with dexamethasone $20 \mathrm{mg}$ on days 1 and 2 , followed by single agent dexamethasone $8 \mathrm{mg}$ bid on days 6 and 7 , and $4 \mathrm{mg}$ bid on day 8 . Forty patients received bleomycin+etoposide+cisplatin (BEP) and a single patient EP. Fifty-one percent of patients had no emesis throughout days $1-5$ and $83 \%$ no delayed emesis days 6-9. The median total duration of nausea of any intensity was $16 \mathrm{~h}$ (primarily mild) over the 216-h study period. Patients reported little interference with daily function as a result of nausea. Eighty-eight percent of patients had no emesis on days 1-2, the days of coadministration of dexamethasone, compared to $83 \%, 68 \%$, and $71 \%$ on days $3-5$. It is of interest to note that no prophylactic antiemetics were given on day 4 of cisplatin, and yet $68 \%$ had no emesis [7].

There are very few data on newer agents such as NK1 receptor antagonists. A phase II study evaluated granisetron plus dexamethasone plus oral aprepitant (125 mg orally on day 1 and $80 \mathrm{mg}$ on each subsequent day of chemotherapy and for two additional days). Thirty-eight patients received highly emetogenic (germ cell tumors or sarcoma) and 40 moderate emetogenic chemotherapy with multiple diagnoses and treatment regimens. The usage of aprepitant did not reveal any new or unexpected safety signals for the 5-7-day course [8]. A phase III double-blinded study of aprepitant is ongoing. Preliminary results also indicated no unique toxicity problems with aprepitant on days 3-7 [9].

The optimal duration of dexamethasone (combined with a 5-HT3 receptor antagonist) is unknown. More severe CINV was noted on days 4 and 5 compared to days 1 and 2 in several studies in which the dexamethasone was given only on the first 2 days of cisplatin combination chemotherapy $[5,7]$. Whether this reflects delayed CINV from days 1 and 2 is unknown. Other investigators have evaluated ondansetron plus dexamethasone $20 \mathrm{mg}$ intravenously on each of the 5 days of cisplatin, and a similar trend was noted. There was no emesis in $100 \%, 88 \%, 67 \%$, $67 \%$, and $73 \%$ of 24 patients on days $1-5$, respectively. Twenty-five to $29 \%$ of patients had three or more emetic episodes on days 3-5, despite the daily administration of both ondansetron and dexamethasone [10]. The side effects of five consecutive days of dexamethasone followed by three additional dosages on days 6-8 for delayed nausea and vomiting and repeated courses every 3 weeks for three to four courses are often underreported and not necessarily trivial. Vardy et al. prospectively evaluated dexamethasone toxicity for prophylaxis of delayed emesis in 60 patients receiving moderately emetogenic chemotherapy. Patients reported moderate to severe problems with insomnia (45\%), indigestion or epigastric discomfort (27\%), agitation $(27 \%)$, weight gain (16\%), and acne (15\%) [11]. Of more concern was the potential for late toxicity from dexamethasone. Four of 47 patients $(9 \%)$ with testicular cancer developed avascular necrosis of the hip [12]. Similar complications have been noted in our testicular cancer population at Indiana University. Whether this is related to the dexamethasone is conjectural, but suggestive.

\section{Guidelines}

Patients receiving multiple-day cisplatin should receive a 5HT3 receptor antagonist plus dexamethasone for acute nausea and vomiting and dexamethasone for delayed nausea and vomiting.

MASCC level of confidence: high

MASCC level of consensus: unanimous

ESMO level of evidence: II

ESMO grade of recommendation: A

\section{High-dose chemotherapy}

There are still very few data on the effective use of modern antiemetics for patients treated with high-dose chemotherapy with stem cell support. Most are phase II studies of a 5-HT3 receptor antagonist alone or combined with dexamethasone. One of the major problems is that nausea and vomiting is due to multiple causes, including prophylactic antibiotics, narcotic analgesics that are used for mucositis, as well as the chemotherapy-induced nausea and vomiting. The use of total-body irradiation can be a confounding factor. Cross-comparison of studies is difficult due to the varied regimens and different patient populations and tumor types. Additionally, there is a variety of high-dose chemotherapy regimens administered over consecutive days. Most patients have experienced emesis with prior chemotherapy or irradiation. These are not only real clinical problems in emesis control, but there are confounding factors that make clinical research in this area, and comparison between different studies is extremely difficult. 
There is very little information on the natural history of chemotherapy-induced nausea and vomiting in patients undergoing high-dose chemotherapy and stem cell transplantation. In a prospective evaluation of 82 patients undergoing high-dose chemotherapy with stem cell transplantation by Ballen et al., antiemetic prophylaxis consisted of at least a 5HT-3 receptor antagonist and steroids. In this study, the most common chemotherapy regimen was cyclophosphamide/ etoposide/BCNU used in lymphoma patients (29\%), followed by thiotepa/melphalan/cyclophosphamide for myeloma patients $(15 \%)$. Twenty-six patients $(32 \%)$ received an allograft, six from an unrelated donor and 20 from a sibling donor; 56 patients $(68 \%)$ received an autograft. The study showed the antiemetic outcome as follows: $95 \%$ of patients had nausea during the first week of treatment, and $80 \%$ of the patients had at least one emetic episode. The percentage of patients with emesis was as follows: day $1,13 \%$; day $2,21 \%$; day $3,30 \%$; day $4,38 \%$; day $5,44 \%$; day $6,39 \%$; day $7,18 \%$. In multivariate analysis, gender, emesis with prior chemotherapy, history of morning or motion sickness, type of transplant (auto vs. allo), use of total-body irradiation, or use of dexamethasone did not impact emesis control [13].

Similar findings were reported in an observational study in 100 consecutive transplant patients. In this trial, LopezJimenez et al. reported a CR rate in only $20 \%$ of patients with the usage of 5-HT3 receptor antagonists [14].

Mandanas et al. reported a randomized phase III study in 197 patients with a variety of tumor types including breast cancer, and Hodgkin's and non-Hodgkin's lymphoma receiving a variety of high-dose chemotherapy regimens. Patients were randomized to either dolasetron IV on day 1 and a single dose orally $8-12 \mathrm{~h}$ later or ondansetron IV on day 1 followed by a single oral dose of $8 \mathrm{mg} 8-12 \mathrm{~h}$ later. The CR rate was $45.7 \%$ and $46.9 \%$, respectively. The authors concluded that dolasetron and ondansetron are equally safe and effective in this setting [15].

Paul et al. conducted a phase II trial with high-dose chemotherapy and stem cell transplantation in 42 patients to evaluate the efficacy of a triple therapy regimen consisting of a 5-HT3 receptor antagonist, aprepitant, and dexamethasone. The CR rate was $42.9 \%$ [16].

Musso et al. studied the usage of palonosetron plus dexamethasone in 134 patients treated with high-dose chemotherapy and autologous stem cell transplantation for hematological malignancies. In this trial, dexamethasone was administered throughout the entire treatment period. CR rate was only $36 \%$; however, $50 \%$ of the patients were retreated with palonosetron for breakthrough emesis and were successfully rescued [17].

In summary, it is apparent that the control of nausea and vomiting with high-dose chemotherapy and stem cell transplantation remains a challenge. Few randomized trials have been done in the setting of high-dose chemotherapy. These trials are underpowered and use different end points compared to the standard antiemetic trials, making study comparison as well as interpretation very difficult. Recommendations are based on phase II studies performed in patients with a variety of different risk factors, tumor types, and different preparatory regimens or underpowered phase III trials. Delayed emesis appears to be a major problem, and only a few studies have been reported with the usage of aprepitant. Standard therapy appears to be a 5-HT3 receptor antagonist with dexamethasone with or without aprepitant.

\section{Refractory emesis and rescue antiemetics}

Antiemetics are most effective when used prophylactically since emesis in progress is much more difficult to suppress and raises the specter of an added component of anticipatory nausea or vomiting on future treatment cycles. It is therefore preferable to use maximally effective antiemetics as first-line therapy rather than withholding more effective antiemetics for later use or use at the time of antiemetic failure. If vomiting continues to occur even with the use of a maximally effective antiemetic regimen, then alternative non-chemotherapy-related causes of nausea and vomiting, such as bowel obstruction, increased intracranial pressure, renal failure, sepsis, electrolyte imbalance, or concomitant medications must be considered.

There are very few large studies of rescue antiemetic therapy for chemotherapy-induced emesis. Much of the literature in this area consists of exploratory studies of therapy for refractory emesis, defined as additional treatment with a new antiemetic strategy in later cycles for patients in whom nausea or vomiting appeared during a first cycle of chemotherapy in spite of standard antiemetic treatment. Both pharmacologic interventions, such as cannabinoids and olanzapine [18], and non-pharmacologic interventions, such as electroacupuncture [19], have had suggestions of activity when evaluated in this manner. Several of the present major antiemetics were also tested as therapy for refractory emesis at the time of their introduction. Ondansetron has shown activity in patients with emesis refractory to other antiemetics [20]. Route of administration may play a role, with the oral route more effective for ondansetron than the intramuscular route [21]. In general, however, rotation of antiemetics within a given family of antiemetic agents would be unlikely to lead to additional benefit. Recent data suggesting that the mechanism of action of palonosetron may differ from that of other serotonin antagonists [22] could provide a rationale for additional activity with this agent. More recently, several 
studies [23, 24] have documented antiemetic activity of the NK-1 antagonists in patients who did not achieve complete protection from emesis when treated with dexamethasone and a serotonin receptor antagonist alone.

Although the availability of antiemetics for the treatment of refractory emesis is gratifying, the logical strategy would be to include such agents in first-line prophylactic antiemetic regimens so that rescue therapy would not be necessary. Future studies will concentrate on identifying the most efficient and cost-effective strategies for using newer antiemetics to achieve this goal.

Conflict of interest statement The following authors either received research funding or honoraria, or have been a consultant to or an expert witness for: Grunberg - GSK, Helsinn, Merck, Eisai, Prostrakan; Rapoport-Merck; Rittenberg-Merck; Feyer-GSK, Helsinn, Merck. Einhorn (wife) has been an investor in GSK.

\section{References}

1. Einhorn LH, Rapoport B, Koeller J et al (2005) Antiemetic therapy for multiple-day chemotherapy and high-dose chemotherapy with stem cell transplant: review and consensus statement. Supp Care Cancer 13:112-116

2. Somerfield MR, Einhaus K, Hagerty KL et al (2008) American society of clinical oncology clinical practice guidelines: opportunities and challenges. J Clin Oncol 26:4022-4026

3. Herman TS, Einhorn LH, Jones SE et al (1979) Superiority of Nabilone over prochlorperazine as antiemetics in patients receiving chemotherapy. N Eng J Med 300:1295-1297

4. Einhorn LH, Nagy C, Werner K et al (1990) Ondansetron: a new antiemetic for patients receiving cisplatin chemotherapy. J Clin Oncol 8:731-735

5. Fox SM, Einhorn LH, Cox E et al (1993) Ondansetron versus ondansetron, dexamethasone and chlorpromazine in the prevention of nausea and vomiting associated with multiple-day cisplatin chemotherapy. J Clin Oncol 11:2391-2395

6. Sledge GW, Einhorn LH, Nagy C et al (1992) Phase III doubleblind comparison of intravenous ondansetron and metoclopramide as antiemetic therapy for patients receiving multiple-day cisplatinbased chemotherapy. Cancer 70:2524-2528

7. Einhorn LH, Brames MJ, Dreicer R et al (2007) Palonosetron plus dexamethasone for prevention of chemotherapy-induced nausea and vomiting in patients receiving multiple-day cisplatin chemotherapy for germ cell cancer. Supp Care Cancer 15:1293-1300

8. Jordan K, Kinitz I, Voigt W et al (2009) Safety and efficacy of a triple antiemetic combination with the NK-1 antagonist aprepitant in highly and moderately emetogenic multiple-day chemotherapy. Eur J Cancer 45:1184-1187

9. Brames MJ, Johnson E, Nichols C et al (2009) Phase III study of granisetron + dexamethasone $+/-$ aprepitant in patients with germ cell tumors undergoing 5 day courses of cisplatin-based combination chemotherapy: a Hoosier Oncology Group (H.O.G.) study. Supp Care Cancer 17:871-872, abstract

10. Baltzer L, Pisters KMW, Kris MG et al (1993) High dose ondansetron plus dexamethasone for the prevention of nausea and vomiting with multiple day cisplatin chemotherapy. Proc Amer Soc Clin Oncol 12:462, abstract

11. Vardy J, Chiew KS, Galica J, Pond GR, Tannock IF (2006) Side effects associated with the use of dexamethasone for prophylaxis of delayed emesis after moderately emetogenic chemotherapy. Brit J Cancer 94:1011-1015

12. Cook AM, Dzik-Jurasz Ask, Padhani AR, Norman A, Huddart RA (2001) The prevalence of avascular necrosis in patients treated with chemotherapy for testicular tumors. Brit J Cancer 85:1624 1626

13. Ballen KK, Hesketh AM, Heyes C, Becker PS, Emmons RV, Fogarty K, LaPointe J, Liu Q, Hsieh CC, Hesketh PJ (2001) Prospective evaluation of antiemetic outcome following high-dose chemotherapy with hematopoietic stem cell support. Bone Marrow Transplant 28:1061-1066

14. López-Jiménez J, Martín-Ballesteros E, Sureda A, Uralburu C, Lorenzo I, del Campo R, Fernández C, Calbacho M, GarcíaBelmonte D, Fernández G (2006) Chemotherapy-induced nausea and vomiting in acute leukemia and stem cell transplant patients: results of a multicenter, observational study. Haematologica 91:84-91

15. Mandanas RA, Beveridge R, Rifkin RM, Wallace H, Greenspan A, Asmar L (2005) A randomized, multicenter, open-label comparison of the antiemetic efficacy of dolasetron versus ondansetron for the prevention of nausea and vomiting during high-dose myeloablative chemotherapy. Support Cancer Ther 2:114-121

16. Paul B, Trovato JA, Thompson J, Badros AZ, Goloubeva O (2009) Efficacy of aprepitant in patients receiving high-dose chemotherapy with hematopoietic stem cell support. J Oncol Pharm Pract 16:45-51

17. Musso M, Scalone R, Crescimanno A, Bonanno V, Polizzi V, Porretto F, Bianchini C, Perrone T (2009) Palonosetron and dexamethasone for prevention of nausea and vomiting in patients receiving high-dose chemotherapy with auto-SCT. Bone Marrow Transplant 45:123-127

18. Warr D (2008) Chemotherapy- and cancer-related nausea and vomiting. Curr Oncol 15:S4-S9

19. Choo SP, Kong KH, Lim WT, Gao F, Chua K, Leong SS (2006) Electroacupuncture for refractory acute emesis caused by chemotherapy. J Altern Complement Med 12:963-969

20. Seynaeve C, de Mulder PH, Lane-Allman E, van Liessum PA, Verweij J (1991) The 5-HT3 receptor antagonist ondansetron reestablishes control in refractory emesis induced by non-cisplatin chemotherapy. Clin Oncol 3:199-203

21. Fabi A, Ciccarese M, Metro G, Savarese A, Giannarelli D, Nuzzo CM, Russillo M, Sperduti I, Carbone I, Bria E, Cognetti F (2008) Oral ondansetron is highly active as rescue antiemetic treatment for moderately emetogenic chemotherapy: results of a randomized phase II study. Support Care Cancer 16:1375-1380

22. Rojas J, Stathis M, Thomas AG, Massuda EB, Alt J, Zhang J, Rubenstein E, Sebastiani S, Cantoreggi S, Snyder SH, Slusher B (2008) Palonosetron exhibits unique molecular interactions with the 5-HT 3 receptor. Anesth Analg 107:469-478

23. Hesketh PJ, Younger J, Sanz-Altamira P, Hayden M, Bushey J, Trainor B, Krentzin M, Nowd P, Arnaoutakis K, Hesketh AM (2009) Aprepitant as salvage antiemetic therapy in breast cancer patients receiving doxorubicin and cyclophosphamide. Support Care Cancer 17:1065-1070

24. Oechsle K, Muller MR, Hartmann JT, Kanz L, Bokemeyer C (2006) Aprepitant as salvage therapy in patients with chemotherapy-induced nausea and emesis refractory to prophylaxis with 5-HT3 antagonists and dexamethasone. Onkologie 19:557-561 